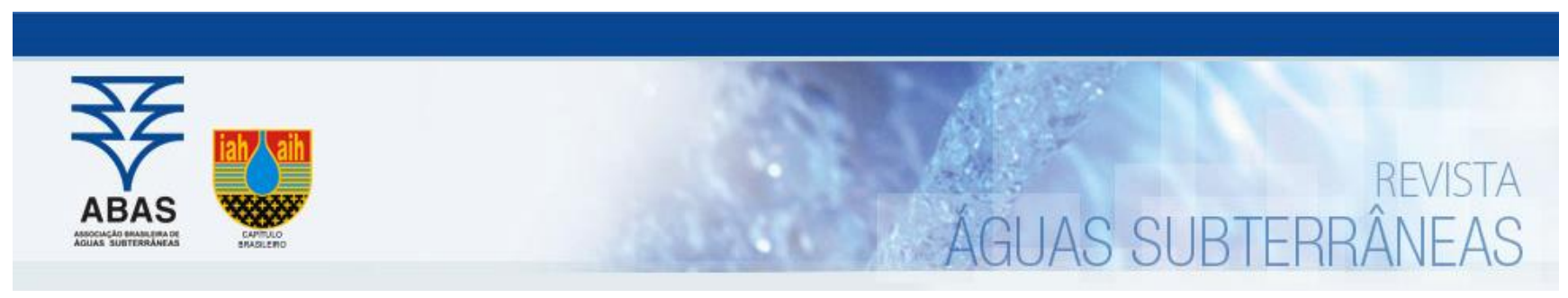

Artigos

\title{
Parâmetros Hidrodinâmicos do Aquífero Cárstico-Fissural da Região de Lagoa Santa, Minas Gerais
}

\author{
Hydrodynamic Parameters of The Karst-Frissure Aquifer of Lagoa Santa \\ Region, Minas Gerais
}

\author{
Rodrigo Sérgio de Paula1; Gabriela Meira Teixeira1; Carolina Gomes Ribeiro1; Pedro Henrique Pereira da Silva1; Thais Guedes \\ Ayres Silva $^{1}$; Luisa Costa Martins Vieira1; Leila Nunes Menegasse Velásquez ${ }^{1}$
}

1 Universidade Federal de Minas Gerais (UFMG), Belo Horizonte, MG

rodrigo.spdm@yahoo.com.br, gabrielameira1998@gmail.com, cgrcarol@gmail.com, phpereira.silva@gmail.com, thaisguedes2@hotmail.com, luisacmvieira@gmail.com, menegase@yahoo.com.br

Condutividade hidráulica.

Grupo Bambuí.

Hidrogeologia.

\section{Palavras-chave:}

Resumo

A área de estudo abarca a totalidade da região denominada de APA Carste de Lagoa Santa e seus entornos, totalizando $505 \mathrm{~km}^{2}$ e distando $35 \mathrm{~km}$ a norte de Belo Horizonte. A área tem sido alvo de vários empreendimentos que preveem um aumento pela exploração e consumo de água. Diante deste crescimento e da fragilidade do sistema cárstico, tornase de fundamental importância o entendimento dos parâmetros hidrodinâmicos de forma a conhecer as características desse sistema aquífero. Geologicamente, a região é representada pelas rochas carbonáticas e metapelíticas do Grupo Bambuí, em um contexto local de intensa deformação rúptil, que regem o sentido de fluxo da água subterrânea, de oeste para leste, e determinam as características dos parâmetros hidrodinâmicos. 0 objetivo do trabalho foi obter os valores de condutividade hidráulica (K), transmissividade (T) e coeficiente de armazenamento (S) pela avaliação de ensaios de recuperação utilizando os métodos de Hvorslev, Bower e Rice e Cooper-Bredehoeft-Papadopulos. Foram utilizadas aplicações de fórmulas matemáticas de Hvorslev para obtenção de K e T, e avaliação do sistema de fraturas a partir de equações matemáticas para obtenção de k. Para a avaliação dos métodos propostos, foram analisados 99 ensaios de recuperação e 1163 fraturas a fim de avaliar a condutividade hidráulica. Os resultados foram comparados de modo a examinar o método mais representativo para o sistema cárstico-fissural e sua representatividade na região. Os três métodos clássicos apresentaram valores parecidos para K e T, sendo o valor modal do armazenamento (10-4) obtido pelo método de Cooper, Bredehoef e Papadopulos. O método matemático de Snow se mostrou mais eficiente para o cálculo de $\mathrm{K}$ em subsuperfície $(10-3 \mathrm{~m} / \mathrm{s})$ estando próximo dos valores encontrados por ensaios de traçadores corantes por outros autores, possibilitando diferenciar os níveis verticais de condutividade hidráulica nesse sistema.

Abstract

Keywords:

Hydraulic conductivity.

Bambuí Group.

Hydrogeology.

Revisado por pares.

Recebido em: 15/03/2020.

Aprovado em: 13/07/2020.
The study area covers the entire region called APA Karst of Lagoa Santa and its surroundings, totalizing $505 \mathrm{~km}^{2}$ of area extension, $35 \mathrm{~km}$ distant from Belo Horizonte/MG-Brazil. The area has been the center of several undertakings which foresee an increase in the exploration and consumption of water. Due to this growth and the karst system fragility, it becomes of main importance the understanding of the hydrodynamic parameters in order to know the particularities of this aquifer system. Geologically, the region is represented by the carbonatic and metapelitic rocks of the Bambui Group, in a local context of intense brittle deformation, which govern the groundwater flow direction, from west to east, and determine the particularities of the hydrodynamic parameters. The work purpose was to obtain the values of hydraulic conductivity $(\mathrm{K})$, transmissivity $(\mathrm{T})$, and storage coefficient $(\mathrm{S})$ through the evaluation of recovery tests applying the methods of Hvorslev, Bower e Rice and Cooper-Bredehoeft-Papadopulos. Applications of Hvorslev's mathematica formulas were used to $\mathrm{K}$ and $\mathrm{T}$, and the fracture system evaluation were performed using the mathematical methodology to K. In order to evaluate the proposed methods, 99 recovery tests and 1163 fractures were analyzed for the hydraulic conductivity evaluation. The results were compared in order to assess the most representative method of the karst-fractured system and its representativity in the region. The three classical methods showed similar $\mathrm{K}$ and $\mathrm{T}$ values, with the modal storage value (10-4) achieved by Cooper, Bredehoef e Papadopulos method. The Snow method was more efficient to calculate $\mathrm{K}$ in subsurface $(10-3 \mathrm{~m} / \mathrm{s})$ being close to the values found by outher authors using tracers. (2019), thereby making it possible to distinguish the vertical levels of hydraulic conductivity in this system.

\section{INTRODUÇÃO}

O termo "carste" designa a paisagem marcada por cavernas e sistemas de águas subterrâneas desenvolvida em rochas solúveis. A ação da água subterrânea emoldura carstificações produzidas pela conjunção da alta solubilidade da rocha e da existência de porosidade secundária bem desenvolvida (WHITE, 2003; FORD e WILLIANS, 2007).

A ciência do carste melhorou a compreensão dos ambientes 
cársticos, sua fragilidade e seu valor para o desenvolvimento humano. Isso porque grandes áreas continentais livres de gelo da Terra são formadas por carstes e aproximadamente 20 a 25\% da população mundial depende das águas subterrâneas provenientes deles (FORD e WILLIAMS, 2007).

Considerando a aleatoriedade da distribuição das superfícies de fraturas e de acamamento, vias preferenciais da circulação de águas e, consequentemente, de processos de dissolução, os aquíferos cársticos são caracterizados por elevada anisotropia e heterogeneidade (LEGRAND e LAMOREAUX, 1975; FORD e WILLIAMS, 1991). Isso é observado ao se analisar a grande variação da condutividade hidráulica dentro de um aquífero cárstico, ressaltando a heterogeneidade deste sistema. 0 mesmo se aplica à direção de medição da condutividade em um ponto, que é independente da direção de medição evidenciando a anisotropia deste aquífero.

O cálculo de suas propriedades hidrodinâmicas requer uma análise mais apurada. Goldscheider e Drew (2007) citam a existência do "Hydraulic conductivity-scale effect" ao enfatizar que os resultados de condutividade hidráulica em aquíferos cársticos são consequências diretas da heterogeneidade. Segundo eles, as condutividades hidráulicas de testes de bombeamento têm influência de macrofraturas, os quais geram resultados mais elevados.

Feitosa et al. (2008) ressaltam que, embora os sistemas cársticos não satisfaçam as condições para a aplicação de métodos para interpretação de testes de bombeamento, é possível a aplicação de alguns métodos para obtenção da transmissividade e do armazenamento. No entanto, os resultados não devem ser extrapolados, sendo representativos apenas para as imediações do poço testado.

Segundo White (2002), os aquíferos cársticos podem ser descritos como tendo tripla permeabilidade, cujos campos de fluxo operam através de cada uma delas em diferentes escalas: permeabilidade da matriz da rocha sã, permeabilidade de fraturas e permeabilidade de protocondutos.

O conhecimento dos parâmetros dos aquíferos cársticos, mesmo sendo pontuais, ou com as ressalvas anteriormente comentadas, é de fundamental importância para o conhecimento da dinâmica de fluxo subterrâneo e da produtividade do aquífero. Desta forma, este estudo objetivou o cálculo desses parâmetros, com destaque para a condutividade hidráulica. Esses são calculados por métodos clássicos, baseados em ensaios de recuperação (Slug test) e por aplicações da equação de Snow (1969) a partir da avaliação das fraturas.

\section{CARACTERÍSTICAS FÍSICAS DA ÁREA DE ESTUDO}

A área possui cerca de $505 \mathrm{Km}^{2}$, localizada a aproximadamente $35 \mathrm{~km}$ a norte de Belo Horizonte, e envolve parcial ou integralmente os municípios de Lagoa Santa, Vespasiano, Funilândia, Confins, Matozinhos, Pedro Leopoldo e Prudente de Morais. Engloba por completo os $350 \mathrm{~km}^{2}$ da região denominada APA Carste de Lagoa Santa e entornos (Figura 1).

Figura 1 - Mapa de localização da área de estudo, com destaque para os limites da APA Carste de Lagoa Santa

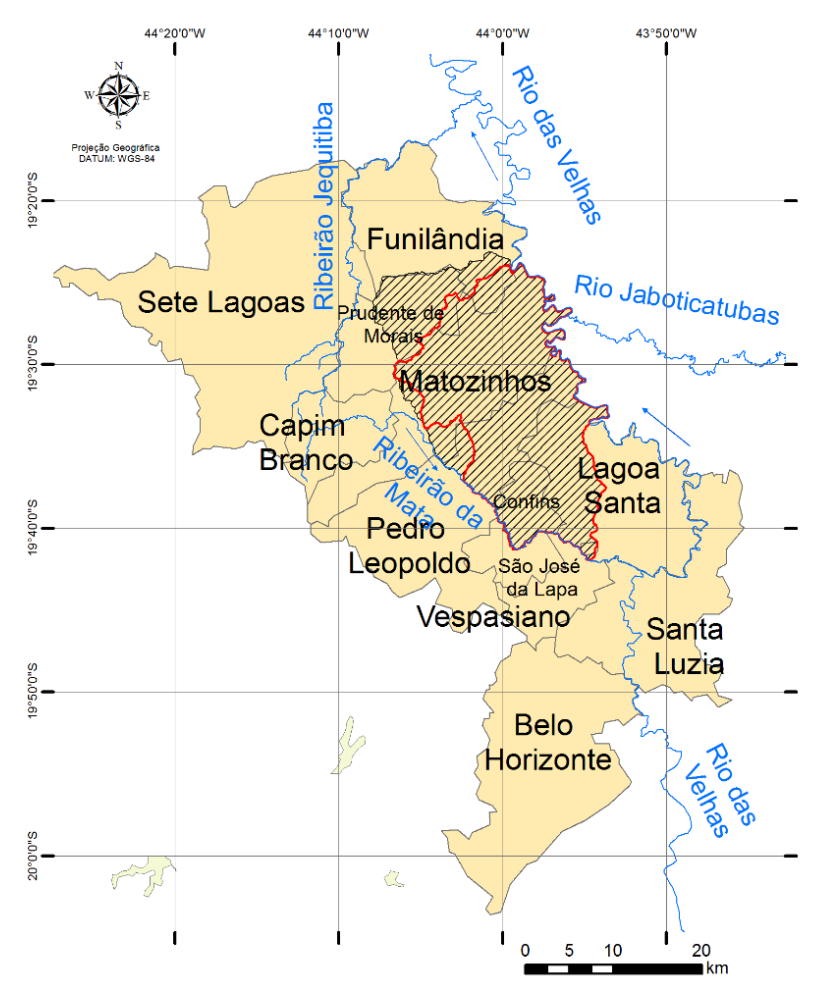

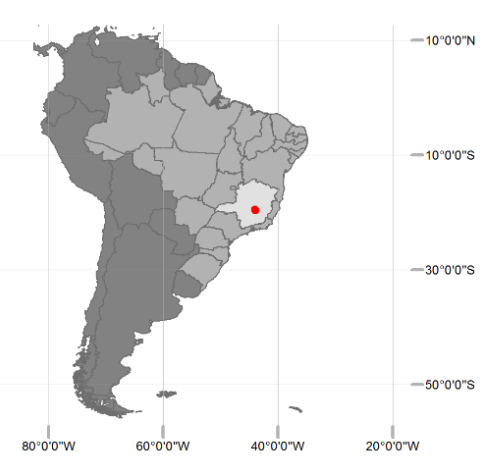

Legenda

Área de estudo

- no contexto nacional

$\square$ Limites APA

Área de estudos

Hidrografia

Municípios

Sentido do fluxo

superficial dos

principais rios 
CLIMA -As classificações climáticas desta região são bastante diversificadas. Koppen se fundamenta na precipitação e na temperatura média do ar e classifica o clima como Aw, tropical, cujas características consistem em duas estações bem definidas: inverno seco e verão chuvoso (VIANA, KOHLER e TAVARES, 1998).

A série histórica de precipitação anual foi analisada para o período de 1980 a 2019, registrada pelas estações Lagoa Santa (1943049), Vespasiano (1943049), Pedro Leopoldo (1944009) e Sete Lagoas (OMM:8670), sendo as três primeiras disponíveis nos sites do Instituto Nacional de Meteorologia - INMET (2017) e a última na Agencia Nacional de Águas ANA (2017).

O ano hidrológico na região pode ser dividido em duas estações bem definidas: seca (abril a setembro) e chuvosa (outubro a março). A média da precipitação anual encontrada foi de $1254,9 \mathrm{~mm}$, distribuídos em 92 dias do ano, sendo que $88,8 \%$ do volume de água precipitada ocorre durante a estação chuvosa. Os valores temperatura apresenta uma variação histórica com médias mínimas de $15,9^{\circ} \mathrm{C}$ com predomínio nos meses de julho a agosto e médias máximas em torno de $28,5^{\circ} \mathrm{C}$ registrado entre dezembro a janeiro.

HIDROGRAFIA - A área é bordejada a leste pelo rio das Velhas, que atua como nível de base da região, com variações de cotas de $660 \mathrm{~m}$ a $630 \mathrm{~m}$ dentro da área. A sudoeste e oeste, a área é balizada pelo ribeirão da Mata, afluente direto do rio das Velhas (Figura 2).

A área de estudo é composta por seis bacias de drenagens de menor porte, que são denominadas de: Palmeira, Jaguara, Escrivânia, Gordura, Jaque e Flor. Elas têm seus córregos com os mesmos nomes, drenando direta ou indiretamente para margem esquerda do rio das Velhas. A exceção é o córrego Samambaia que emerge em um sumidouro, sendo sua região de descarga desconhecida a partir deste ponto.

GEOMORFOLOGIA - Á área é formada por um sistema cárstico desenvolvido, com abundância de feições de dissolução, maciços fraturados, sumidouros, dolinas, surgências e cavernas.
Conforme descrito por Pessoa (2005), as três primeiras feições representam um indicativo de um sistema cárstico desenvolvido:

Ribeiro et al. (2017) fizeram uma análise estatística de dados levantados na região, incluindo maciços carbonáticos, dolinas, cavernas e sumidouros. Nessa análise, $72 \%$ dos maciços apresentavam com ocorrência de dolinas e sumidouros na mesma área, e que $67 \%$ do total destes afloramentos apresentavam a ocorrência de dolinas, sumidouros e cavernas.

GEOLOGIA - A área de estudo é composta, da base para o topo, pelo complexo gnássico-granítico-migmatítico denominado de complexo Belo Horizonte, sobreposto pelas rochas carbonáticas e siliclásticas do Grupo Bambuí, que por sua vez é formada pelas formações Sete Lagoas e Serra de Santa Helena.

O Complexo Belo Horizonte é caracterizado por rochas de bandamento gnáissico de cor cinza-claro, frequentemente exibindo bandamento composicional e feições de migmatização (NOCE, TEIXEIRA, MACHADO 1997). Essas rochas se encontram presentes em uma estreita faixa na porção sul e oeste (Figura 3).

Imediatamente sobre o complexo Belo Horizonte se encontram as rochas carbonáticas da Formação Sete Lagoas, sendo essa subdividida em dois membros. O Membro Pedro Leopoldo na base é formado por calcários de coloração clara e granulometria fina, normalmente encontrado de formada laminada, representados por calcissiltitos impuros. 0 membro Lagoa Santa, no topo, é formado por calcarenitos de coloração mais escura com calcissiltitos e calciruditos subordinados.

O membro Pedro Leopoldo ocorre na porção sul e oeste da área junto aos granitos e na região a leste, compreendendo parte da bacia do córrego Jaque e Flor. Já o membro Lagoa Santa cobre mais de $60 \%$ de toda a área de estudo, sendo distribuído por toda a região (Figura 3). 
Figura 2 - Mapa das bacias hidrográficas da área de estudo com ênfase nas feições geomorfológicas

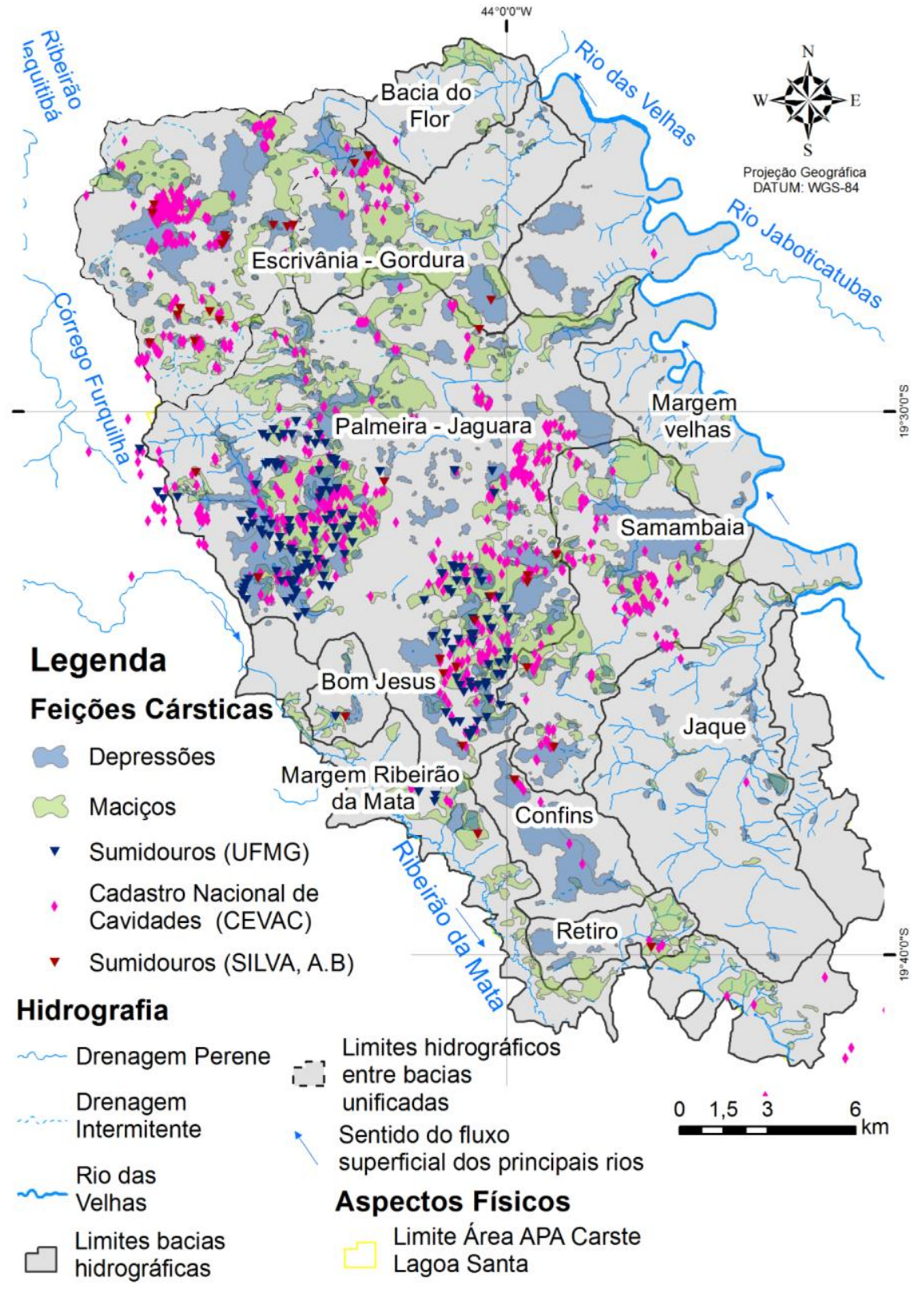


Figura 3 - Mapa Geológico (adaptado de Ribeiro et al., 2003), com destaque para área da APA - Carste de Lagoa Santa

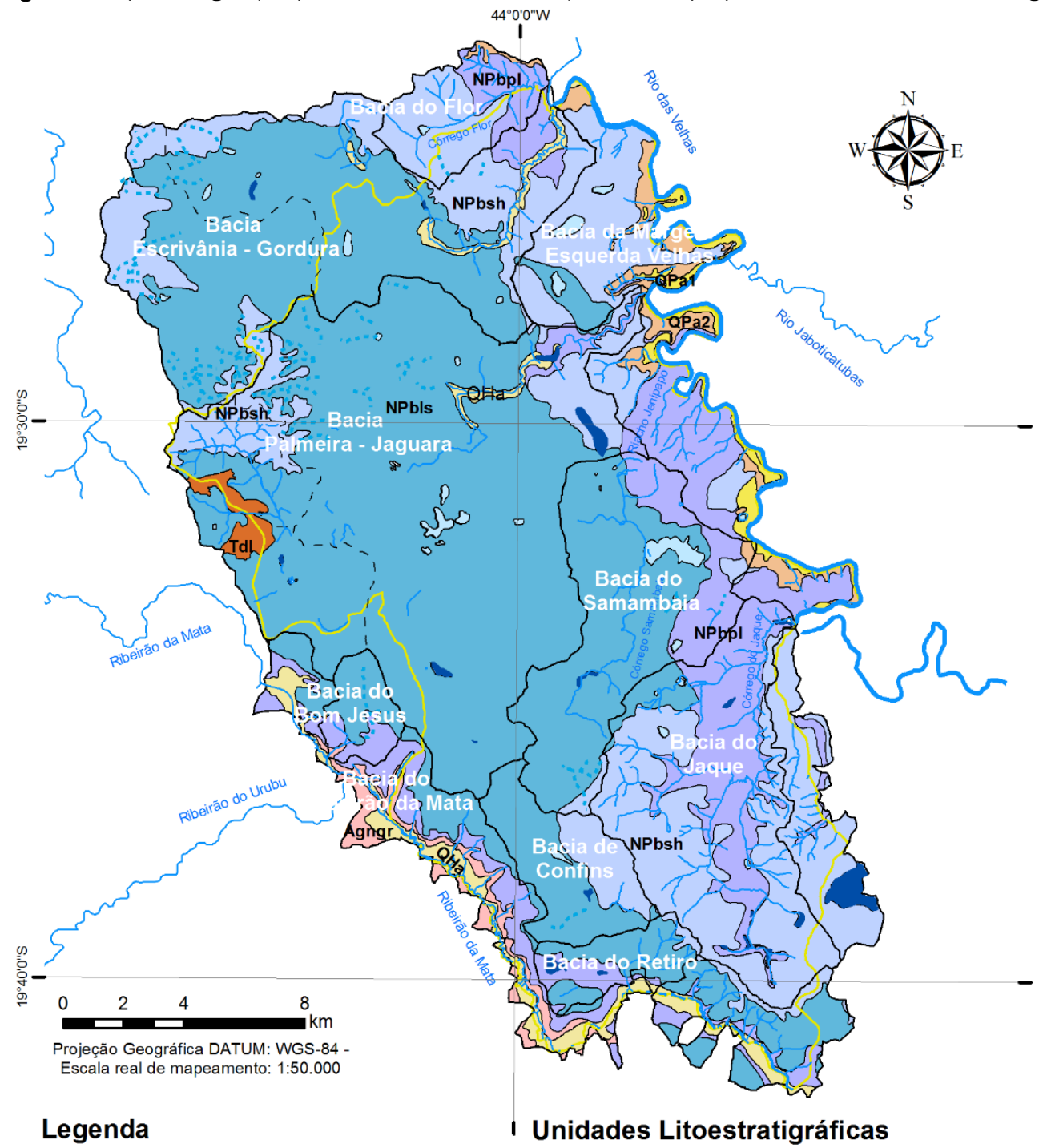

\section{Hidrografia}

$\sim$ Perene

Intermitente

Rio das Velhas

$\approx \approx=$ Ribeirão da Mata

$\square$ Limite das bacias hidrográficas

$\mathrm{I}_{-}^{-}$Limites hidrográfico das bacais incorporadas

Lagoas - Levantamento 1:25.000

Intermitente

S Perene

\section{Aspectos Físicos}

Limite - APA Carste Lagoa Santa

\section{Unidades Litoestratigráficas}

\section{Coberturas Cenozóicas}

\begin{tabular}{|c|c|}
\hline $\mathrm{QHa}$ & $\begin{array}{l}\text { Aluvião: cascalho fino a grosso, areia } \\
\text { fina a grossa, silte e argila }\end{array}$ \\
\hline QPa1 & $\begin{array}{l}\text { Terraço aluvial: sedimentos areno-argilosos } \\
\text { com grânulos de quartzo }\end{array}$ \\
\hline $\mathrm{QPa} 2$ & $\begin{array}{l}\text { Terraço aluvial: sedimentos conglomeráticos, } \\
\text { arenosos e argilosos inconsolidados }\end{array}$ \\
\hline Tdl & $\begin{array}{l}\text { Coberturas Detrito-Lateríticas: solo laterítico, } \\
\text { areno-argiloso, concreções ferruginosas, } \\
\text { fragmentos de quartzo }\end{array}$ \\
\hline nr & zóico \\
\hline NPbsh & $\begin{array}{l}\text { Fm. Serra de Santa Helena: pelítos, arenitos, lentes } \\
\text { carbonáticas, margas e calcarenitos finos }\end{array}$ \\
\hline NPbls & $\begin{array}{l}\text { Fm. Sete Lagoas - Membro Lagoa Santa: calcarenitos } \\
\text { com intercalações de calcissiltitos,estromatólitos }\end{array}$ \\
\hline NPbpl & $\begin{array}{l}\text { Formação Sete Lagoas - Membro Pedro Leopoldo: } \\
\text { calcissiltitos, calcarenitos finos }\end{array}$ \\
\hline อ? & \\
\hline Agngr & $\begin{array}{l}\text { Migmatitos, granitóides, gnaisses a hornblenda; } \\
\text { biotita gnaisse diopsidio- anfibólio-gnaisse }\end{array}$ \\
\hline
\end{tabular}

Sobre a formação carbonática, se encontram rochas argilocarbonáticas da Formação Serra de Santa Helena. Estão localizados em toda a região leste da área, em pequenas porções
Devido ao aprofundamento da bacia em direção leste, a espessura do calcário varia de algumas dezenas de metros na região próxima ao embasamento cristalino, podendo chegar a mais de 300 metros em regiões próximas ao rio das Velhas. 
ao norte e noroeste (Figura 3), assim como nas coberturas cenozoicas que afloram predominantemente nas margens dos córregos.

HIDROGEOLOGIA - A região é representada pela presença de sistemas aquíferos cársticos semiconfinados a livres, sendo bastante produtivos e vulneráveis. A conformação desses aquíferos está vinculada à presença dos carbonatos com feições de dissolução, tais como dolinas em superfície e cavidades em profundidade, as quais, de maneira interligada, formam uma rede de condutos e fendas alargados pela ação da água (VIANA, KOHLER, TAVARES, 1998).

O embasamento, representado por um aquífero fissural de baixo potencial produtivo, aflora restritamente na borda da bacia. A unidade aquífera da formação Serra de Santa Helena, composta pelo metapelitos intemperizados, forma aquitardos ou, localmente, aquíferos pobres. Essa unidade geológica e as coberturas cenozoicas podem atuar localmente como zonas de recarga localizada para os aquíferos sotopostos (PESSOA, 2005). Estas zonas localizadas de recarga apresentam taxas de infiltrações diferentes conforme a permeabilidade dos litotipos.

Sabendo que a condutividade hidráulica em meio carste está diretamente relacionada com a abertura das fraturas, pressupõem que os valores de condutividade são influenciados pelas fraturas e condutos de dissolução. Conforme a elevação da pressão confinante com o aumento da profundidade, pressupõe que as fraturas e condutos de dissolução tendem a se fechar em profundidade. Desta forma é provável que se encontre, no mínimo, dois níveis distintos de condutividade hidráulica, sendo um relacionado ao nível fraturado em profundidade e o outro controlado por condutos de dissolução mais superficiais.
Os valores de transmissividade da região são controlados pelos níveis de condutividade hidráulica, uma vez que a espessura da unidade aquífera carbonática se mostra não se presenta muito espessa.

\section{MATERIAIS E MÉTODOS}

Com o objetivo de diferenciar a condutividade hidráulica do sistema aquífero cárstico superior, da condutividade do sistema cárstico-fissural inferior, foi considerado o fechamento das estruturas rúpteis em profundidade. Para tanto, foi utilizada a Lei Cúbica de Snow (1969) para a determinação da condutividade hidráulica por meio da abertura e espaçamentos das fraturas do aquífero superior. Já os testes de recuperação em poços tubulares foram utilizados com o intuito de determinar a condutividade hidráulica no aquífero inferior. Os resultados encontrados foram comparados com outros métodos aplicados por distintos autores de forma a validar ou não os procedimentos empregados.

\subsection{Aquífero Cárstico - Fissural}

Para fins de comparação entre métodos, os parâmetros hidráulicos da porção mais profunda do aquífero foram obtidos por três métodos distintos (Tabela 1), empregando-se o Software Aquifer Test 3.5:

- Hvorslev (1951) e Bower e Rice (1976) - para obtenção da condutividade hidráulica (K), equações 1 e 2 respectivamente;

- Cooper-Bredehoeft-Papadopulos (1967) - para obtenção de transmissividade (T) e de armazenamento (S) (Equação 3).

Tabela 1 - Comparação das considerações adotadas em cada um dos métodos

\begin{tabular}{|c|c|c|}
\hline $\begin{array}{l}\text { HVORSLEV } \\
\text { (1951) }\end{array}$ & $\begin{array}{l}\text { BOWER e RICE } \\
\text { (1976) }\end{array}$ & $\begin{array}{l}\text { COOPER- BREDEHOEFT-PAPADOPULOS } \\
(1967)\end{array}$ \\
\hline $\begin{array}{l}\text { Aquífero confinado ou livre com extensões } \\
\text { laterais infinitas, homogêneo e espessura } \\
\text { uniforme; }\end{array}$ & $\begin{array}{l}\text { Aquífero confinado ou livre com extensões } \\
\text { laterais infinitas, homogêneo e espessura } \\
\text { uniforme; }\end{array}$ & $\begin{array}{l}\text { Aquífero confinado sem drenança com ex- } \\
\text { tensões laterais infinita, homogêneo, isotró- } \\
\text { pico e espessura uniforme; }\end{array}$ \\
\hline $\begin{array}{l}\text { Superfície potenciométrica inicialmente ho- } \\
\text { rizontal; }\end{array}$ & $\begin{array}{l}\text { Superfície potenciométrica inicialmente ho- } \\
\text { rizontal; }\end{array}$ & $\begin{array}{l}\text { Superfície potenciométrica inicialmente ho- } \\
\text { rizontal; }\end{array}$ \\
\hline $\begin{array}{l}\text { Poço de bombeamento total ou parcial- } \\
\text { mente penetrante; }\end{array}$ & $\begin{array}{l}\text { Poço de bombeamento total ou parcial- } \\
\text { mente penetrante; }\end{array}$ & $\begin{array}{l}\text { Poço de bombeamento totalmente pene- } \\
\text { trante; }\end{array}$ \\
\hline $\begin{array}{l}\text { Volume de água injetado/retirado instanta- } \\
\text { neamente do poço; }\end{array}$ & $\begin{array}{l}\text { Volume de água injetado/retirado instanta- } \\
\text { neamente do poço; }\end{array}$ & $\begin{array}{l}\text { Volume de água injetado/retirado instanta- } \\
\text { neamente do poço; }\end{array}$ \\
\hline Regime permanente; & Regime permanente. & Regime transiente; \\
\hline $\begin{array}{l}\text { Coeficiente de armazenamento é desconsi- } \\
\text { derado e a condutividade é obtida pontual- } \\
\text { mente. }\end{array}$ & & $\begin{array}{l}\text { Direção de fluxo horizontal; } \\
\text { Água liberada instantaneamente do armaze- } \\
\text { namento com rebaixamento da carga hi- } \\
\text { dráulica. }\end{array}$ \\
\hline
\end{tabular}

- Equação de Hvorslev

$$
K=\frac{r^{2} \ln \left(\frac{L_{e}}{R}\right)}{2 L_{e} T_{0}}
$$


onde:

$\mathrm{K}=$ Condutividade Hidráulica $(\mathrm{m} / \mathrm{s})$

$r=$ Raio do Revestimento $(\mathrm{m})$

$\mathrm{R}=$ Raio do Poço $(\mathrm{m})$

$\mathrm{L}_{\mathrm{e}}=$ Comprimento do Filtro $(\mathrm{m})$

$\mathrm{T}_{0}=$ Tempo que leva para o nível d'água cair 37\% da variação inicial $\left(\mathrm{m} / \mathrm{s}^{2}\right)$

- $\quad$ Equação de Bower e Rice

$k=\frac{r^{2} \ln \left(\frac{R e}{r_{w}}\right)}{2 L_{e}} \frac{1}{T} \ln \left(\frac{h_{0}}{h}\right)$

onde:

$\mathrm{K}=$ Condutividade Hidráulica $(\mathrm{m} / \mathrm{s})$

$r=$ Raio do Poço $(m)$

$\mathrm{R}_{\mathrm{e}}=$ Raio do Revestimento $(\mathrm{m})$

$r_{\mathrm{w}}=$ Raio Efetivo do Teste $(\mathrm{m})$

$\mathrm{L}_{\mathrm{e}}=$ Comprimento do Filtro $(\mathrm{m})$

$\mathrm{T}=$ Tempo em que $\mathrm{h}=\mathrm{h}_{0}(\mathrm{~m})$

$\mathrm{h}_{\mathrm{o}}=$ Rebaixamento no Tempo Zero $(\mathrm{m})$

$\mathrm{h}=$ Rebaixamento no Tempo $\mathrm{t}(\mathrm{m})$

- Equação de Cooper, Bredehoef e Papadopulos

$H=\frac{H_{0} r_{w} S k_{0}(r q)}{T q\left(r_{w} q k_{0}\left(r_{w} q\right)+2 \alpha k_{1}\left(r_{w} q\right)\right)}$

$q=\sqrt{p S} / T$

$\propto=\frac{r_{w}^{2} S}{r_{c}^{2}}$

onde:

$\mathrm{H}=$ Rebaixamento do Poço $(\mathrm{m})$

$r=$ Rebaixamento Inicial do Poço $(m)$

$r=$ Raio do Poço $(m)$

$r_{c}=$ Raio do Revestimento $(m)$

$r_{\mathrm{w}}=$ Raio Efetivo do Teste $(\mathrm{m})$

$\mathrm{t}=$ Tempo Decorrido do Teste (s)

$\mathrm{S}=$ Armazenamento $(\mathrm{m})$

$\mathrm{T}=$ Transmissividade $\left(\mathrm{m}^{2} / \mathrm{s}\right)$

$p=$ Variável da transformada de Laplace

$q=\operatorname{vazão}\left(m^{3} / s\right)$

$\mathrm{K}_{0}$ e $\mathrm{K}_{1}=$ Função Modificada de Bessel de Ordem 0 e 1

$\propto$ Constante em Relação ao Poço

Os valores de condutividade hidráulica para o método de Cooper-Bredehoeft-Papadopulus (1967), assim como os valores de transmissividade para os métodos de Hvorslev (1951) e Bower e Rice (1976), foram obtidos pela relação da condutividade e transmissividade com a espessura do aquífero (Equação 6). Para a espessura do aquífero foi considerada a média de profundidade dos poços tubulares $(90 \mathrm{~m}$ ) utilizados para avaliação dos ensaios de recuperação.
Os valores dos parâmetros obtidos pelos três métodos visaram determinar, para cada um deles, o intervalo modal.

$T=K x b$

onde:

$\mathrm{T}=$ Transmissividade $\left(\mathrm{m}^{2} / \mathrm{s}\right)$

$\mathrm{K}=$ Condutividade Hidráulica $(\mathrm{m} / \mathrm{s})$

$\mathrm{b}=$ Espessura do Aquífero $(\mathrm{m})$

Os dados utilizados para os cálculos dos parâmetros compreendem a espessura do aquífero e os resultados dos ensaios de recuperação de 99 poços tubulares disponibilizados pelo Sistema de Informações de Água Subterrânea (SIAGAS), pelo Companhia de Saneamento de Minas Gerais (COPASA), pelo Instituto Mineiro de Gestão das Águas (IGAM), por meio da Superintendência Regional de Meio Ambiente (SUPRAM) e pela empresa HIDROPOÇOS LTDA. Ressalta-se que os poços utilizados, apesar de estarem localizados no aquífero carbonático, podem receber água das unidades metapelíticas (superior) ou granítica (inferior), originando poços mistos, o que influenciaria os valores obtidos dos parâmetros hidrodinâmicos.

Apesar de as metodologias apresentadas terem sido concebidas para aquíferos homogêneos, Feitosa et al. (2008) ressalta que os valores obtidos de Transmissividade e de Armazenamento, na ausência métodos mais adequados, são representativos apenas para as imediações dos poços. Os autores sugerem ainda que, em uma amostra estatística dos parâmetros, deve-se considerar sempre o valor modal como o mais representativo do aquífero cárstico, dado que a média é assimétrica e muitas vezes não representativa.

Conforme exposto por Feitosa et al. (2008), foi então proposto o cálculo da abrangência de cada ensaio de recuperação. Desta forma, avaliou-se o raio de influência de cada ensaio de recuperação pelo método de Theis (Equações 7 e 8).

$$
\begin{aligned}
& w(\mu)=\frac{(s \times 4 \times \pi \times T)}{Q} \\
& r=\sqrt{ } \frac{(\mu \times 4 \times T \times t)}{S}
\end{aligned}
$$

onde:

$w(\mu)=$ Função do Poço

$\mathrm{r}=$ Raio $(\mathrm{m})$

$\mathrm{s}=$ Rebaixamento $(\mathrm{m})$

$\mathrm{u}=$ Função de $w(\mu)$

$\mathrm{T}=$ Transmissividade $\left(\mathrm{m}^{2} /\right.$ dia $)$

$\mathrm{Q}=$ Vazão $\left(\mathrm{m}^{3} /\right.$ dia $)$

$\mathrm{t}=$ Tempo $(\mathrm{dia})$

$\mathrm{S}=$ Armazenamento

\subsection{Aquífero Cárstico}

Para avaliação da condutividade hidráulica da porção mais carstificada (superior) da unidade aquífera da Formação Sete Lagoas, foi aplicada a Lei Cúbica de Snow (1969) para meios fraturados, a qual leva em consideração o espaçamento e abertura das fraturas (Equação 9). A partir da abertura e do 
espaçamento das fraturas levantados por Ribeiro et al (2016), foi calculada a condutividade hidráulica de cada fratura individualmente. Em seguida, os dados foram tratados estatisticamente de acordo com sua direção. Devido ao processo de dissolução acentuado em superfície, fraturas com alto grau de dissolução e protocondutos medidos em campo não foram utilizados. Isso porque a abertura excessiva destas estruturas não pode ser correlacionada com meio subterrâneo pois estas estruturas rúpteis tendem a se fechar, em profundidade. Posteriormente, o resultado encontrado com os dados de fraturas foi comparado com a velocidade aparente de ensaios de traçadores corantes em condutos para verificar a eficácia dessa técnica.

$K=(p \times g / 12 u) N b^{3}$ onde:

$K=$ Condutividade Hidráulica $(\mathrm{m} / \mathrm{s})$

$p=$ Densidade da Água $\left(\mathrm{kg} / \mathrm{m}^{3}\right)$

$\mathrm{g}=$ Aceleração da Gravidade $\left(\mathrm{m} / \mathrm{s}^{2}\right)$

$u=$ Viscosidade da Água (kg/m.s)

$N=$ Frequência de Fraturas $(1 / \mathrm{m})$

$\mathrm{b}=$ Abertura de Fraturas $(\mathrm{m})$

Para melhor representatividade do levantamento das fraturas no espaço amostral, a área foi dividida em quadrículas regulares de $9 \mathrm{~km}^{2}$. Foram identificadas famílias de fraturas e mediu-se a atitude, o espaçamento e a abertura de cada uma. Os dados foram normalizados para uma área unitária de $1 \mathrm{~m}^{2}$, totalizando um levantamento de 1163 medidas de fraturas, (9) cobrindo mais de $80 \%$ das quadrículas (Figura 4).

Figura 4 - Mapa de localização dos pontos de medição de fratura, evidenciando o predomínio do caimento das fraturas por quadricula. 


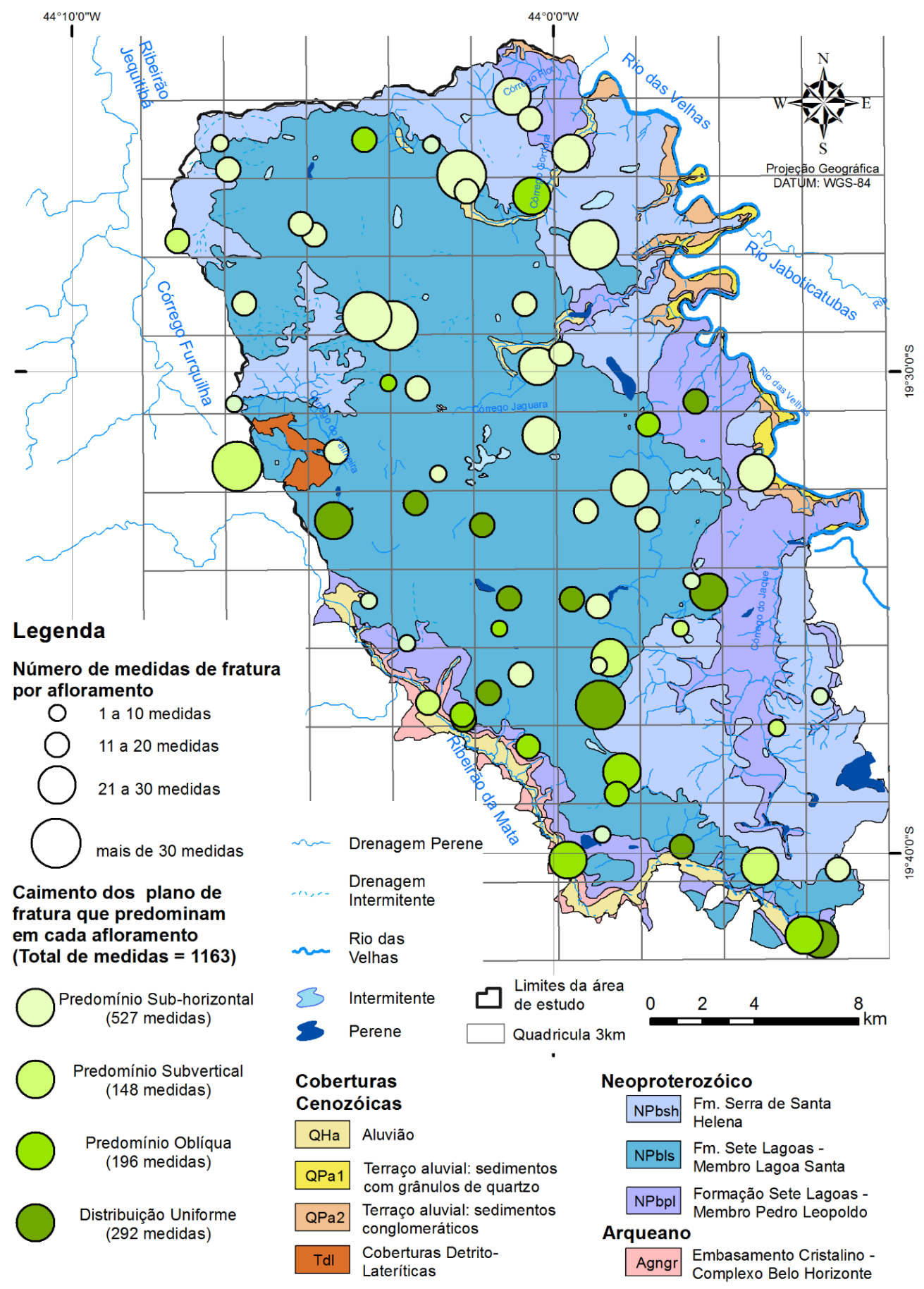

\section{RESULTADOS}

\subsection{Raio de Influência dos Poços}

Com a fórmula de Theis (equações 7 e 8), calculou-se os valores de raio de influência, que apresentaram variação de $10 \mathrm{~m}$ a $2397 \mathrm{~m}$, com média de $302 \mathrm{~m}$ e mediana de $88 \mathrm{~m}$. Esses resultados evidenciaram a anisotropia do aquífero na região, e ressaltaram a importância da utilização de vários métodos e de um extenso banco de dados para avaliar parâmetros hidrodinâmicos.

\subsection{Parâmetros Hidrodinâmicos do Sistema Cárstico Fissural}

Para a avaliação da condutividade hidráulica (K), da transmissividade (T) e do coeficiente de armazenamento (S) do aquífero inferior, utilizaram-se dados de recuperação de nível d'água de ensaios de vazão realizados em 99 poços. Os métodos empregados foram os de Hvorslev (1951), Bower e Rice (1976) e Cooper-Bredehoeft-Papadopulos (1967).

Condutividade Hidráulica (K) - Os valores de condutividade hidráulica dos três métodos oscilaram entre $10^{-9}$ a $10^{-1} \mathrm{~m} / \mathrm{s}$ (Tabela 2). Por outro lado, os valores modais foram bem semeIhantes, variando de 1,25 a $1,91 \times 10^{-7} \mathrm{~m} / \mathrm{s}$.

A relevante diferença entre a média e a mediana calculadas para cada um dos métodos ressalta a anisotropia do aquífero 
cárstico-fissural, assim como o controle do fluxo por tipos distintos de fraturas (Figura 4). 0 intervalo $10^{-8}$ a $10^{-6} \mathrm{~m} / \mathrm{s}$ está compreendido em $97 \%, 75,4 \%$ e $94 \%$ do total dos resultados para os métodos de Hvorslev (1951), Bower e Rice (1976) e Cooper-Bredehoeft-Papadopulos (1967), respectivamente (Figura 5) .

Tabela 2 - Valores de condutividade hidráulica para o compartimento do aquífero cárstico-fissural.

\begin{tabular}{lccc}
\hline \multicolumn{1}{c}{ K (m/s) } & \multicolumn{2}{c}{ CONDUTIVIDADE HIDRÁULICA - K } \\
K mínima & HVORSLEV (1951) & BOWER e RICE (1976) & COOPER BREDEHOEFT PAPADOPU- \\
K média & $5,29 \times 10^{-9}$ & $1,45 \times 10^{-8}$ & $3,51 \times 10^{-9}$ \\
K máxima & $1,57 \times 10^{-3}$ & $8,80 \times 10^{-3}$ & $8,22 \times 10^{-3}$ \\
K mediana & $1,55 \times 10^{-1}$ & $5,00 \times 10^{-1}$ & $8,13 \times 10^{-1}$ \\
K modal & $2,92 \times 10^{-7}$ & $1,10 \times 10^{-6}$ & $1,91 \times 10^{-7}$ \\
\hline
\end{tabular}

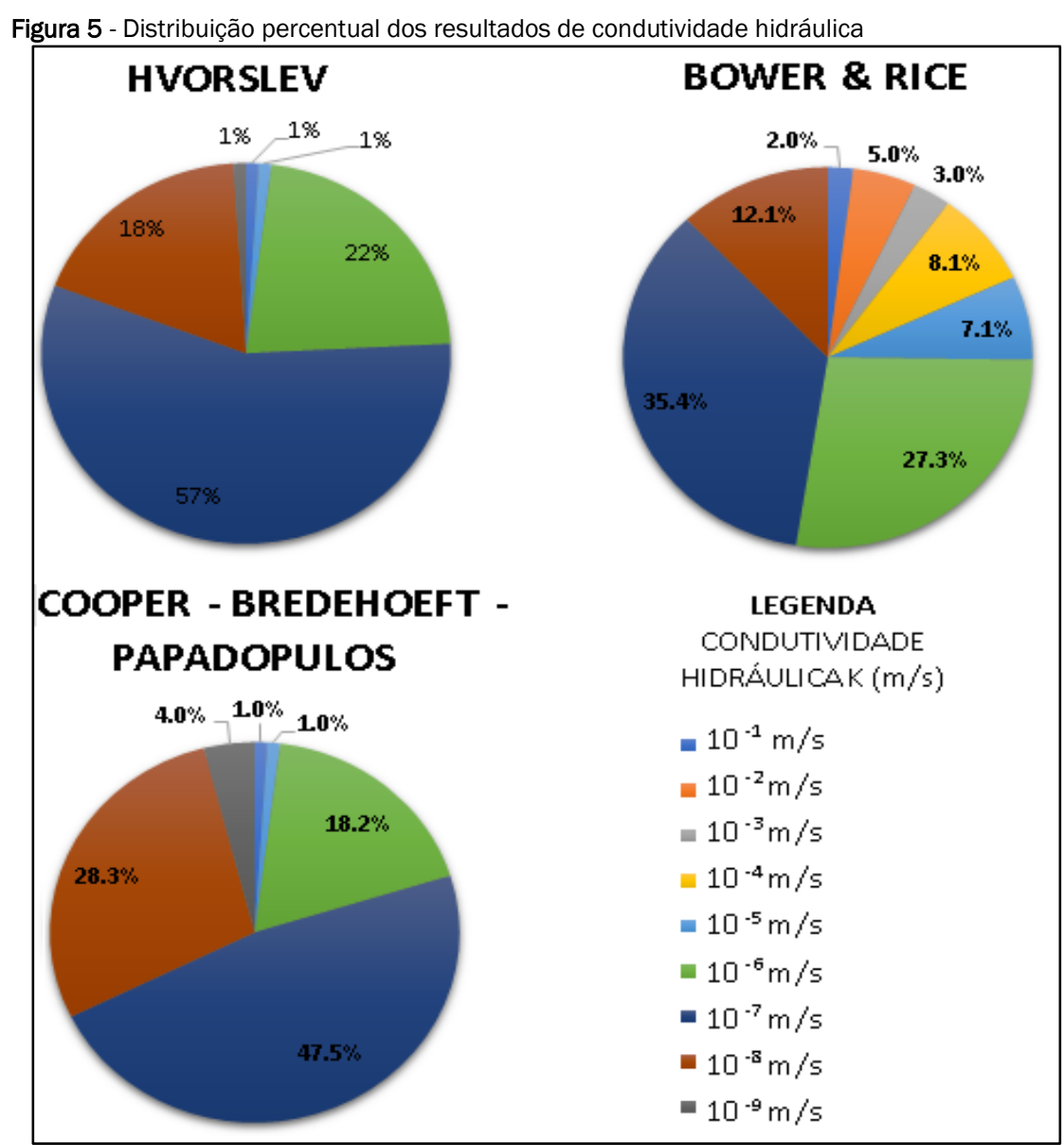

Fonte: Modificado de Paula (2019)

Tais valores são característicos de um sistema fissural, pois os dados modais de $\mathrm{K}$ variando de $10^{-6}$ a $10^{-8} \mathrm{~m} / \mathrm{s}$ perfazem mais de $90 \%$ dos resultados calculados para dois dos três métodos. Os valores modais na ordem de $10^{-7} \mathrm{~m} / \mathrm{s}$ correspondem a mais de $50 \%$ usando a metodologia de Hvorslev. Portanto, os resultados por esse método foram adotados para a continuidade de cálculos e representações da área (Figura 6).

Figura 6 - Mapa da condutividade hidráulica,obtida pelo método de Hvorslev (1951) 


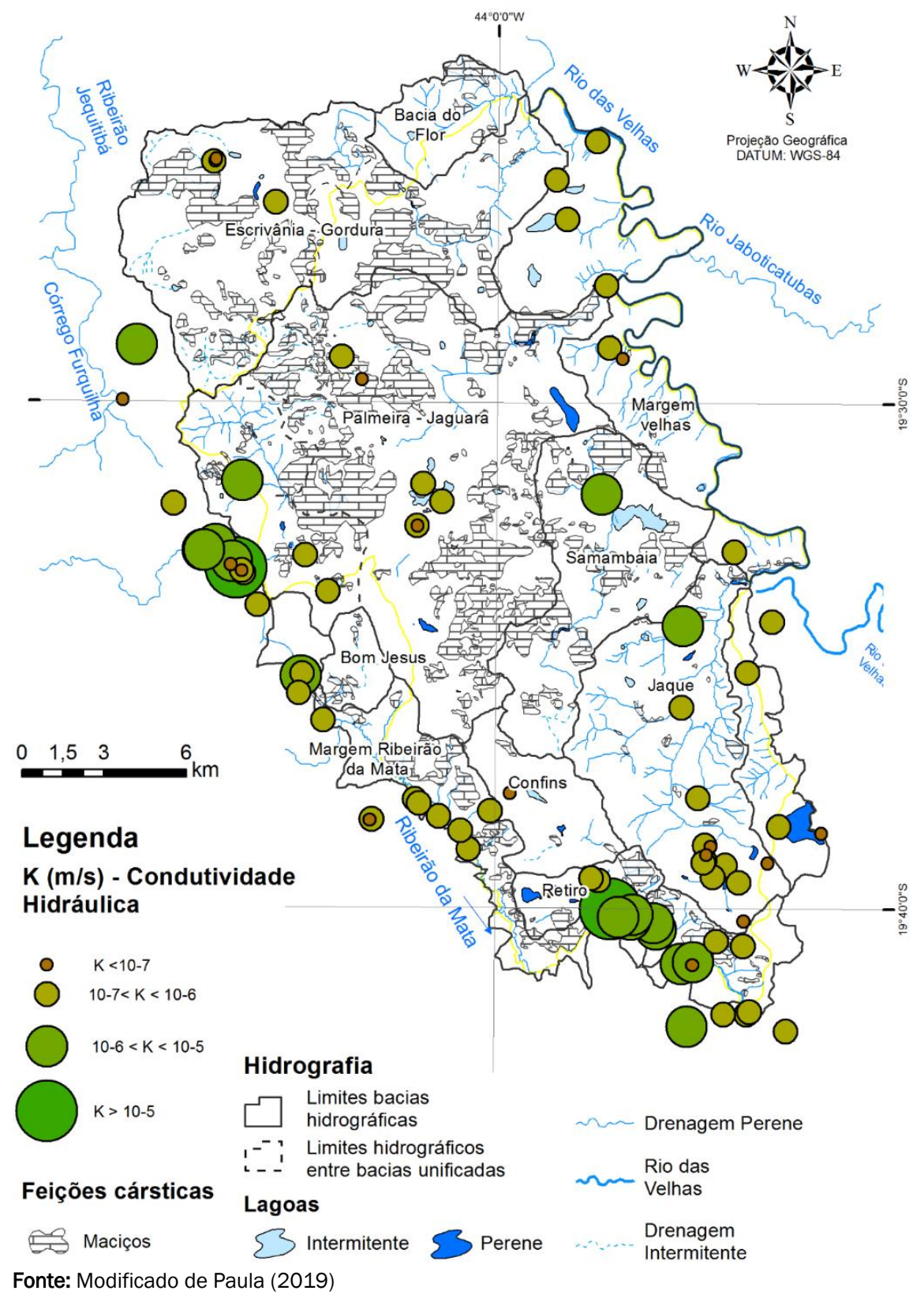

É preciso enfatizar que a ausência de poços com dados descritivos comprometeu os resultados na região centro-norte da área de estudo (Figura 6). Sob outra perspectiva, as maiores condutividades hidráulicas ( $\mathrm{K}>10^{-5} \mathrm{~m} / \mathrm{s}$ ) ocorrem predominantemente nas porções oeste (bacias contíguas PalmeirasBom Jesus) e sul (representado pela bacia do Retiro).

Portanto, assume-se que há maior dissolução cárstica nas bacias Palmeiras-Bom Jesus e em direção ao centro da bacia do Jaguara, por conta do número expressivo de cavernas e sumidouros identificados nessa região por Berbert-Born e Horta (1994) e Berbert-Born, Horta e Dutra (1998), respectivamente. A bacia do Retiro foi interpretada como contendo possíveis falhas NW-SE ou como região de contatos geológicos, que proporciona maior velocidade aparente do fluxo.

Os baixos valores de condutividade hidráulica $\left(\mathrm{K}<10^{-7} \mathrm{~m} / \mathrm{s}\right)$ podem ser atribuídos à presença das unidades não carbonáticas ou carbonáticas impuras. Nas regiões sudeste e noroeste,

por exemplo, os metapelitos da Formação Serra de Santa Helena são interceptados em poços mistos e/ou mais profundos. Na porção nordeste, os poços próximos ao rio das Velhas estão associados a camadas dos calcários mais impuros do Membro Pedro Leopoldo (VIEIRA, 2018). Já na faixa oeste da área, os baixos valores de $\mathrm{K}$ se destacam em duas regiões com poços mistos que alcançaram o embasamento cristalino Pessoa (2005) realizou trinta ensaios de aquífero em piezômetros para a obtenção de condutividade na região sul da área de estudo. Ele encontrou valores médios de $10^{-6} \mathrm{~m} / \mathrm{s}$ pelo método de Hvorslev, coerentes com os obtidos para região (Figuras 5 e 6).

É provável que os valores de condutividade hidráulica sejam maiores do que os calculados. Os poços analisados, apesar de estarem associados à unidade carbonática, podem ser influenciados também pelas suas unidades limitantes, os metapelitos no topo e os granitos na base, as quais possuem condutividades hidráulicas inferiores às do aquífero cárstico. Outras 
possibilidades seriam a interferência de poços em operação próximos ao poço ensaiado ou pela própria perda de carga dentro do próprio poço.

Transmissividade (T) - A transmissividade foi calculada: com base na interpretação dos testes de recuperação, de maneira direta, pelo método de Cooper, Bredehoeft e Papadopulos
(1967); e pelo produto da condutividade hidráulica pela espessura do aquífero nos demais métodos. Para esse último, foi utilizada a espessura média, baseada no valor médio da profundidade dos poços tubulares correspondente a 90 metros (PAULA, 2019). Os resultados variaram de $10^{-7}$ a $10^{+2}$ $\mathrm{m}^{2} / \mathrm{s}$, e o valor modal foi comum entre os métodos, da ordem de $10^{-5} \mathrm{~m}^{2} / \mathrm{s}$ (Tabela 3 ).

Tabela 3 - Valores de transmissividade para o compartimento aquífero cárstico - fissural

\begin{tabular}{lccc}
\multicolumn{1}{c}{$\mathrm{T}\left(\mathrm{m}^{2} / \mathrm{s}\right)$} & HVORSLEV (1951) & BOWER e RICE (1976) & $\begin{array}{c}\text { COOPER BREDEHOEFT PAPADOPU- } \\
\text { LOS (1967) }\end{array}$ \\
\hline T mínima & $7,94 \times 10^{-7}$ & $2,18 \times 10^{-6}$ & $4,50 \times 10^{-7}$ \\
T média & $2,35 \times 10^{-1}$ & $1,27 \times 10^{-0}$ & $1,23 \times 10^{-0}$ \\
T máxima & $2,33 \times 10^{-1}$ & $7,52 \times 10^{1}$ & $1,22 \times 10^{2}$ \\
Tmediana & $3,74 \times 10^{-5}$ & $1,16 \times 10^{-4}$ & $2,57 \times 10^{-5}$ \\
T modal & $10^{-5}(59,6 \%)$ & $10^{-5}(34,3 \%)$ & $10^{-5}(55,6 \%)$ \\
\hline
\end{tabular}

As variações do valor modal da transmissividade em três ordens de grandeza $\left(10^{-4}\right.$ a $\left.10^{-6} \mathrm{~m}^{2} / \mathrm{s}\right)$ representaram $96 \%, 72 \%$ e $96 \%$ do total dos dados para os métodos de Hvorslev, Bower e Rice e Cooper-Bredehoeft-Papadopulos (1967), respectivamente (Tabela 4), obtendo-se, portanto, uma ótima representatividade dos dados dentro desses intervalos.

Tabela 4 - Percentual da ordem de grandeza de transmissividade para o compartimento aquífero cárstico - fissural

\begin{tabular}{cccc}
\hline $\mathrm{T}\left(\mathrm{m}^{2} / \mathrm{s}\right)$ & HVORSLEV (1951) & BOWER e RICE (1976) & $\begin{array}{c}\text { COOPER BREDEHOEFT PAPADOPULOS } \\
(\mathbf{1 9 6 7 )})\end{array}$ \\
\hline$<10^{-7}$ & $1,0 \%$ & $0,0 \%$ & $2,0 \%$ \\
$10^{-6}$ & $14,1 \%$ & $11,1 \%$ & $21,2 \%$ \\
$10^{-5}$ & $59,6 \%$ & $34,3 \%$ & $55,6 \%$ \\
$10^{-4}$ & $22,2 \%$ & $26,3 \%$ & $19,2 \%$ \\
$>10^{-3}$ & $3,0 \%$ & $28,3 \%$ & $2,0 \%$ \\
\hline
\end{tabular}

Adotou-se os valores obtidos pelo método de Hvorslev (1951) para o compartimento cárstico-fissural, por representar maior percentual modal $(59,6 \%)$, com $10^{-5} \mathrm{~m}^{2} / \mathrm{s}$.

Coeficiente de Armazenamento (S) - Para o coeficiente de armazenamento, o método de Cooper-Bredehoeft-Papadopulos foi o único a ser utilizado, posto que é o único dos três trabaIhados que calcula esse parâmetro. Os valores de $\mathrm{S}$ ficaram no intervalo de 10-11 a 10-1, o que indica a larga abrangência de condições, de livres a confinadas, conforme descrito por Feitosa et. al., (2008) aquíferos confinados se apresentam intervalos $10^{-3}>\mathrm{S}>10^{-5}$ ou menores.

Tabela 5 - Percentual da ordem de grandeza do coeficiente de armazenamento para o compartimento aquífero cárstico - fissural.

\begin{tabular}{cc}
\hline S (ordem de grandeza) & PERCENTUAL \\
\hline $10^{-6}$ a $10^{-11}$ & $14,1 \%$ \\
$10^{-5}$ & $16,2 \%$ \\
$10^{-4}$ & $35,4 \%$ \\
$10^{-3}$ & $11,1 \%$ \\
$10^{-2}$ & $7,1 \%$ \\
$10^{-1}$ & $16,1 \%$ \\
\hline
\end{tabular}

Na Figura 7, os maiores valores estão na bacia do Palmeiras, a norte da bacia do Jaguara, na bacia do Retiro e no extremo sudeste da área, indicando grandes volumes de água nessas regiões e elevado potencial aquífero.

Figura 7 - Mapa do coeficiente de armazenamento, obtido pelo método de Cooper, Bredehoef e Papadopulos (1967). 


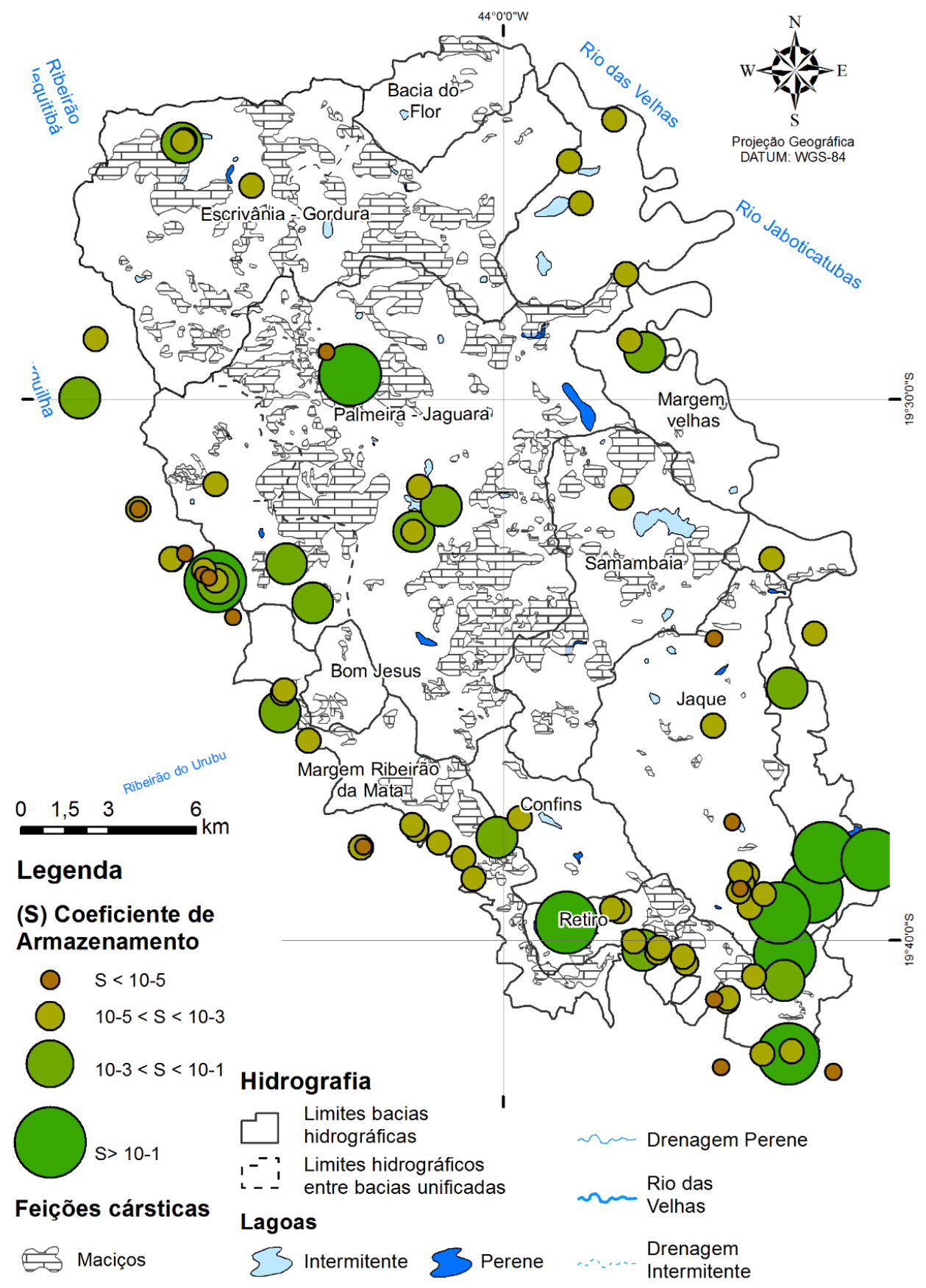

Fonte: Modificado de Paula (2019).

\subsection{Condutividade hidráulica do Sistema Cárstico}

Para as 1163 fraturas que apresentavam abertura menor que $1 \mathrm{~cm}$ e baixo grau de dissolução visível, as condutividades hidráulicas foram calculadas (Tabela 6, Figura 8). A análise foi feita por famílias de fraturas: fraturas sub-horizontais, com caimento entre $0^{\circ}$ e $15^{\circ}$; fraturas oblíquas, com mergulho entre $16^{\circ}$ e $74^{\circ}$; e fraturas subverticais, entre $75^{\circ}$ e $90^{\circ}$. Nessa análise (Tabela 6 ), foi obtido um valor modal na ordem de 10
$3 \mathrm{~m} / \mathrm{s}$ (45\%), com as maiores frequências desse valor para as fraturas sub-horizontais e, em seguida, para as subverticais. Visando exibir o grau máximo de anisotropia da unidade carbonática, calculou-se também as condutividades hidráulicas para as 400 medidas de fraturas com abertura maior que 1 $\mathrm{cm}$, e as mais de 400 medidas de protocondutos. Os valores modais foram de $3,09 \times 10^{1} \mathrm{~m} / \mathrm{s}$ e $7,35 \times 10^{3} \mathrm{~m} / \mathrm{s}$, respectivamente. 


\begin{tabular}{cccc}
\hline K mínimo & $1,46 \times 10^{-4}$ & $5,44 \times 10^{-5}$ & $5,72 \times 10^{-5}$ \\
K médio & $9,30 \times 10^{-1}$ & $3,07 \times 10^{-1}$ & $2,22 \times 10^{-1}$ \\
K máximo & $9,15 \times 10^{1}$ & $3,05 \times 10^{1}$ & $1,14 \times 10^{1}$ \\
K mediana & $3,27 \times 10^{-3}$ & $1,09 \times 10^{-3}$ & $2,29 \times 10^{-3}$ \\
K modal & $2,86 \times 10^{-3}(53,1 \%)$ & $1,63 \times 10^{-3}(40,3 \%)$ & $2,29 \times 10^{-3}(47,7 \%)$ \\
\hline
\end{tabular}

Apesar dos dados representarem fraturas individuais, os valores modais encontrados pela Lei de Snow (1969) são mais elevados que os dos ensaios de recuperação. 0 mesmo se observa ao comparar os valores mínimos e máximos entre os métodos (Tabelas 4 e 6). Isso acontece por se tratar de um compartimento mais carstificado, localizado em regiões superiores da unidade aquífera. Teodoro et al. (2019) obtiveram valor de velocidade média máxima de $10^{-2} \mathrm{~m} / \mathrm{s}$ em seis ensaios por injeção de traçadores corantes em sumidouros com detecção em nascentes de alta vazão, o que indica uma ótima correlação entre os métodos de traçador e a Lei de Snow.

A Figura 8 mostra os sentidos dos caimentos dos planos de fratura: as sub-horizontais caindo predominante para $\mathrm{E}$; as oblíquas, com caimentos principalmente para NE, E e SE; e as subverticais, com mergulhos predominantes para $\mathrm{N}$ e $\mathrm{S}$ (PAULA, 2019).

Visto que o nível de base regional localiza-se a leste da área (rio das Velhas) e analisando-se os principais trends de fraturas (Figura 8), constata-se que o fluxo de água subterrânea ocorre preponderantemente por meio das fraturas sub-horizontais com caimento predominante para leste. Já a formação de condutos de dissolução deve se realizar a partir da interseção das fraturas sub-horizontais com as de alto ângulo de mergulho.

Figura 8 - Diagramas de rosetas do sentido dos mergulhos das fraturas sub-horizontais $(n=501)$, Oblíquas $(n=427)$ e Subverticais $(n=235)$

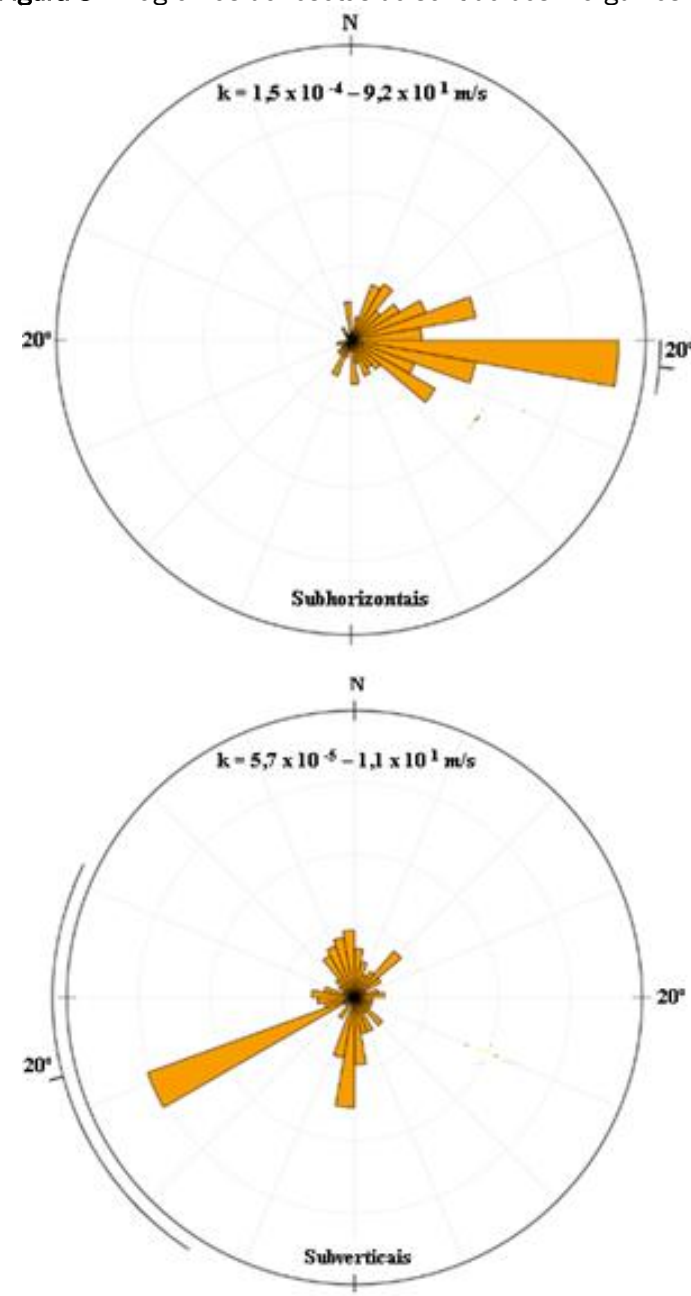

Fonte: Retirado de Paula (2019).

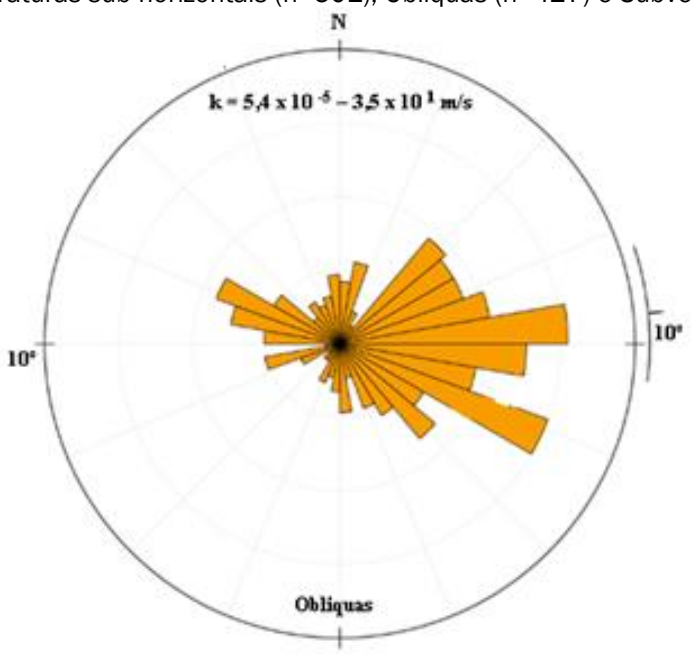

Subhorizonais Obliquas Subverticais

$\begin{array}{llll}\text { Direçăo Principal } & 95^{\circ} & 84,3^{\circ} & 254,8^{\circ} \\ \text { 95\% de Confiança } & 5,1^{\circ} & 12,7^{\circ} & 41,5^{\circ} \\ \text { Medidas } & 501 & 427 & 235 \\ \text { Maximo } & 18.16 \% & 7,73 \% & 15,32 \%\end{array}$

Os resultados encontrados pelo levantamento das estruturas rúpteis são coerentes com os apresentados por Ribeiro et al. 
(2019), que avaliaram atitudes de fraturas e de protocondutos. Segundo os autores, estes últimos possuem direção E-W com suave mergulho para leste e teriam sido formados pela interseção de planos sub-horizontais (acamamento e fraturas) com fraturas de alto ângulos.

\section{CONCLUSÕES}

Ao considerar a ausência de métodos específicos para aquíferos heterogêneos e anisotrópicos, os resultados apresentados neste trabalho devem ser utilizados sempre com cautela, obedecendo às suas premissas e limitações.

Ressalta-se que os resultados obtidos em ensaios de recuperação devem ser utilizados apenas na proximidade da realização do ensaio, não sendo recomendada a extrapolação, visto a grande variação da influência do cone dos poços em aquíferos cárstico-fissurais (de 10 a 2397 metros neste estudo). Outra consideração relevante é o uso de valores modais ao invés de valores médios. Isso porque o valor modal representa o valor de maior frequência de um conjunto de dados amostrados, aproximando-se assim de ambientes anisotrópicos.

Os valores de condutividade hidráulica $(K)$ obtidos pelos métodos de Hvorslev, Bower e Rice, e Cooper, Bredehoeft e Papadopulos, indicam uma boa aproximação para obtenção de $\mathrm{K}$ em aquíferos cárstico-fissurais. Os valores obtidos, além de similares entre si, são coerentes com os calculados por Pessoa (2005) na região.

A grande variabilidade dos parâmetros hidrodinâmicos entre seus valores máximos e mínimos, assim como a abrangência dos raios de influência, reforça a heterogeneidade e anisotropia do sistema cárstico-fissural.

A comparação da lei de Snow com os ensaios de recuperação ressaltou a existência de dois sistemas aquíferos distintos: um aquífero cárstico-fissural mais profundo e um aquífero cárstico mais superficial.

Os resultados de condutividade hidráulica para o aquífero cárstico, obtidos pela aplicação da lei de Snow, mostraram ordem de grandeza semelhantes aos encontrados por Teodoro et al. (2019). Portanto, se averigua a presença de um fluxo de água subterrânea controlado por condutos nas porções mais rasas do aquífero (aquífero cárstico) e um fluxo mais profundo controlado, principalmente, por fraturas (aquífero cárstico-fissural).

Salienta-se que os valores modais de condutividade hidráulica obtidos pelas estruturas rúpteis mais dissolvidas, 3,09 $\times 10^{1}$ $\mathrm{m} / \mathrm{s}$ e $7,35 \times 10^{3} \mathrm{~m} / \mathrm{s}$, revelam o grau de anisotropia do sistema carbonático e a existência de zonas de maior produtividade no aquífero.

Os valores modais de transmissividade obtidos pelos ensaios de recuperação registraram uma moda de $10^{-5} \mathrm{~m}^{2} / \mathrm{s}$. Todavia, devido ao espessamento da bacia para leste, esse valor deve ser usado com restrições.
A representação cartográfica do coeficiente de armazenamento, e da condutividade hidráulica revelou valores elevados para as bacias do Palmeiras e Retiro, exibindo um elevado potencial hídrico para essas regiões.

\section{AGRADECIMENTOS}

Ao Centro Nacional de Pesquisa e Conservação de Cavernas (CECAV/ICMBio) pelo financiamento, Proc. FUNDEP/GERDAU/UFMG No 22.317, Instituto de Geociências da Universidade Federal de Minas Gerais (IGC-UFMG).

\section{REFERÊNCIAS}

ANA. Agência Nacional de Águas (dados pluviométricos da estação Sete Lagoas), 10 mar. de 2017 Disponivel em: http://mapas-hidro.ana.gov.br/Usuario/Esta-

cao.aspx?est=193343540. Acesso em: 10 mar. 2017.

BERBERT-BORN, M. L. C.; HORTA, L. C. S. Espeleologia: Inventário de cavidades naturais região de Matozinhos-Mocambeiro: v. 1 - Belo Horizonte, CPRM, 1994.

BERBERT-BORN, M. L. C.; HORTA, L. C. S, DUTRA, G. M. Levantamento espeleológico. In: CPRM. Série APA Carste de Lagoa Santa: patrimônio espeleológico, histórico e cultural. v.3 Belo Horizonte, 1998.

BOWER, H.; RICE, R. C. A slug test method for determining hydraulic conductivity of unconfined aquifers with completely or partially penetrating wells. Water Resources Research, v. 12, $\begin{array}{llll}n . & \text { p. } & 423-428, & 1976 .\end{array}$ https://doi.org/10.1029/WR012i003p00423

COOPER, H. H., BREDEHOEF, J. D., PAPADOPULOS, S.S. Response of Finite-Diameter Well to an Instantaneous Charge of Water. Water Resources Research, v. 3, n. 1, p. 263-269, 1967. https://doi.org/10.1029/WR003i001p00263

FEITOSA, F. A. C., MANUEL FILHO, J., FEITOSA, E. C., DEMETRIO, J. G. A. Hidrogeologia: conceitos e aplicações. 3. ed. rev e ampl. Rio de Janeiro: CPRM: LABHID, 2008.

FORD, D. C., WILLIAMS, P. W. Karst geomorphology and hidrology. London: Chapman-Hall, 1991.

FORD, D.C., WILLIAMS, P.W. Karst geomorphology and hydrology. 2 ed. John Wiley \& Sons, Chichester, Reino Unido. 2007.

GOLDSCHEIDER N.; DREW, D. Methods in Karst Hydrogeology. International Contributions to Hydrogeology, 26, Londres: Taylor \& Francis, 2007.

HVORSLEV, M. J., Time lag and soil permeability in ground-water observations, Bull. No. 36. Vicksburg, Mississippi: Waterways Exper. Sta. Corps of Engrs, U.S. Army, 1951.

INMET - Instituto Nacional de Meteorologia. Disponível em: http://www.inmet.gov.br/portal/index.php?r=estacoes/estac oesautomaticas. Acesso em: 10 mar. 2017.

LEGRAND, H. E.; LAMOREAUX, P. E. Hydrogeology and hydrology of karst. In: Burger A.; Dubertret, L. Hydrogeology of karstic terrains. (Ed.), Paris:IAH, 1975.

NOCE, C. M.; TEIXEIRA, W.; MACHADO, N. Geoquímica dos gnaisses TTG e granitoides neoarqueanos do Complexo Belo Horizonte, Quadrilátero Ferrífero, Minas Gerais. Revista Brasileira de Geociências, v. 27, n. 01, p 25-32, 1997. https://doi.org/10.25249/0375-7536.19972532

PAULA, R.S. Modelo Conceitual de Fluxo dos Aquíferos 
Pelíticos: Carbonáticos da Região da APA Carste de Lagoa Santa, MG. 2019. Tese de Doutorado - Instituto de Geociências, Universidade Federal de Minas Gerais, Belo Horizonte.

PAULA, R.S., VELÁSQUEZ, L.N.M. Balanço hídrico em sistema hidrogeológico cárstico, região de Lagoa Santa, Minas Gerais. Revista Águas Subterrâneas, v.33, n. 2, p. 119-133, 2019. https://doi.org/10.14295/ras.v33i2.29252

PESSOA, P. F. P. Hidrogeologia do aquífero cárstico coberto de Lagoa Santa, MG. 2005. Tese de Doutorado - Instituto de Geociências, Universidade Federal de Minas Gerais, Belo Horizonte.

RIBEIRO, J. H.; TULLER, M. P.; FILHO, A. D.; PADILHA, A. V.; CÓRDOBA, C.V. Projeto VIDA: mapeamento geológico, região de Sete Lagoas, Pedro Leopoldo, Matozinhos, Lagoa Santa, Vespasiano, Campim Branco, Prudente de Morais, Confins e Funilândia, Minas Gerais - relatório final, escala 1:50.000. 2. ed. Belo Horizonte: CPRM, 2003. https://doi.org/10.14295/ras.v33i1.29148

RIBEIRO, C. G.; MEIRELES, C. G., LOPES, N. H. B., ARCOS, R. E. C. Levantamento Geológico Estrutural Aplicado aos Fluxos dos Aquíferos Cárstico - Fissurais da Região da APA Carste de Lagoa Santa, Minas Gerais. 2016. Trabalho de Graduação - Instituto de Geociências, Universidade Federal de Minas Gerais, Belo Horizonte.

RIBEIRO, C. G.; VELASQUEZ, L. N. M., AMARAL, D. G. P., MURTA, M. C. P., SILVA, P. H. P., PAULA, R. S. Utilização de Feições Exocársticas para Identificação de Áreas Favoráveis à Ocorrência de Cavidades e Sumidouros. In: SIMPÓSIO DE GEOLOGIA EM
DIAMANTINA. GEOSUDESTE, 2017, Diamantina. Anais [...]Diamantina: SBG, 2017 1p.

RIBEIRO, C. G., VELÁSQUEZ, L. N. M., PAULA, R. S., MEIRELES, C. G., LOPES, N.H.B, ARCOS, R.E.C., AMARAL, D.G.P. Análise de fluxos nos aquíferos cárstico-fissurais da região da APA Carste de Lagoa Santa, MG. Revista Águas Subterrâneas, v. 33, n. 1, p. 12-21, 2019.

SNOW, D. T., Anisotropic Permeability of Fractured Media. Water Resources Research, v.5, n.6, p. 1273-1289, 1969. https://doi.org/10.1029/WR005i006p01273

TEODORO, M. I. P., VELÁSQUEZ, L. N.M, FLEMING, P. M., PAULA, R. S., SOUZA, R. T., DOI, B. M. Hidrodinâmica do Sistema Aquífero Cárstico Bambuí, com uso de traçadores corantes, na região de Lagoa Santa, Minas Gerais. Revista Águas Subterrâneas, Belo Horizonte, v. 33, n. 4, p. 392-406, 2019. https://doi.org/10.14295/ras.v33i4.29532

VIANA, H. S.; KOHLER, H. C.; TAVARES, V. P. (Org.). APA Carste de Lagoa Santa: meio físico - Volume I. Belo Horizonte: IBAMA/CPRM, 1998.

VIEIRA, L. C. M. Hidrogeoquímica dos Aquíferos da Região da APA Carste de Lagoa Santa, MG. 2018. Dissertação de Mestrado - Instituto de Geociências, Universidade Federal de Minas Gerais, Belo Horizonte.

WHITE, W. B. 2002. Karst hydrology: recent developments and open questions. Engineering Geology, 65, 2002. p. 85-105. https://doi.org/10.1016/S0013-7952(01)00116-8

WHITE, W. B. 2003. Conceptual models for karstic aquifers. Speleogenesis and Evolution of Karst Aquifers 1, 1, 6p, 2003. 